\title{
Phase 1a study of the CDK4/6 inhibitor, FCN-437c, in Chinese patients with HR +/HER2- advanced breast cancer
}

\author{
Jian Zhang ${ }^{1} \cdot$ Xiaojia Wang $^{2} \cdot$ Xian Wang $^{3} \cdot$ Aimin $\mathrm{Hui}^{4} \cdot$ Zhuli Wu $^{5} \cdot$ Ling Tian $^{6} \cdot$ Changjiang Xu $^{5} \cdot$ Yuchen Yang $^{5}$. \\ Wenjing Zhang ${ }^{5}$. Xichun $\mathrm{Hu}^{1}$
}

Received: 20 February 2021 / Accepted: 19 May 2021 / Published online: 9 June 2021

(c) The Author(s) 2021

\begin{abstract}
Summary Purpose This phase 1a, first-in-human study assessed the safety, maximum tolerated dose (MTD), pharmacokinetics (PK), and antitumor activity of FCN-437c, a cyclin-dependent kinase 4 and 6 (CDK4/6) inhibitor. Methods The study enrolled female patients with HR +/HER2- advanced breast cancer (BC) who failed standard of care therapy. A $3+3$ doseescalation design was utilized with a starting dose of $50 \mathrm{mg}$ daily for 3 weeks on and 1 week off treatment in 28-day cycles. Patients received escalating doses of FCN-437c monotherapy (50, 100, 200, 300, and $450 \mathrm{mg})$. Results Seventeen patients received FCN-437c $50 \mathrm{mg}(n=3), 100 \mathrm{mg}(n=3), 200 \mathrm{mg}(n=3), 300 \mathrm{mg}(n=6)$, and $450 \mathrm{mg}(n=2)$. Two patients who received the 450-mg dose experienced dose-limiting toxicities (DLTs; grade 4 thrombocytopenia and neutropenia); no DLT was observed at any other dose level. Frequently reported treatment-emergent adverse events (TEAEs) of any grade were hematological: leukopenia (94.1\%), neutropenia $(88.2 \%)$, anemia $(64.7 \%)$, and thrombocytopenia $(47.1 \%)$. Grade 3-4 TEAEs included neutropenia (64.7\%) and leukopenia (47.1\%). Exposure of FCN-437c increased almost proportionally to doses ranging from 50 to $200 \mathrm{mg}$. At doses from 200 to $450 \mathrm{mg}$, there appeared to be a trend of saturation. The MTD was determined to be $300 \mathrm{mg}$. Of 15 patients with measurable disease, nine (60.0\%) patients experienced stable disease; no complete or partial responses were observed. Conclusions These results established an acceptable safety profile for FCN-437c in patients with advanced BC, and there were no unexpected signals relative to other CDK4/6 inhibitors. (NCT04488107; July 13, 2020)
\end{abstract}

Keywords CDK4/6 inhibitor $\cdot$ FCN-437c $\cdot$ Safety $\cdot$ Pharmacokinetics $\cdot$ Antitumor activity

\section{Introduction}

Xichun $\mathrm{Hu}$

xchu2009@hotmail.com

1 Department of Medical Oncology, Fudan University Shanghai Cancer Center, 270 Dong an Road, Shanghai 200032, China

2 Department of Breast Medical Oncology, Cancer Hospital of the University of Chinese Academy of Sciences (Zhejiang Cancer Hospital), 1 Banshan East Street, Gongshu District, Hangzhou 310022, China

3 Department of Medical Oncology, Sir Run Run Shaw Hospital, 3 Qingchun East Road, Hangzhou 310016, China

4 Fosun Pharma USA Inc, 91 Hartwell Ave Suite 305, Lexington, MA 02421, USA

5 Beijing Fosun Pharmaceutical Research and Development Co., Ltd, 1289 Yishan Road, Shanghai 200233, China

6 Avanc Pharmaceutical Co., Ltd, 55 Songshan Street, Jinzhou 121013, China
Breast cancer (BC) has become the most common lifethreatening malignancy in women worldwide. Although many approaches have been developed for the diagnosis and treatment of $\mathrm{BC}$, the 5-year survival rate of metastatic $\mathrm{BC}$ remains at 27\% [1]. Cyclin-dependent kinases 4 and 6 (CDK4/6) play an important role in cell proliferation and are often dysregulated in $\mathrm{BC}$, particularly in hormone-receptor (HR)-positive disease [2, 3]. Cyclin D1 is a transcriptional target of the estrogen receptor (ER) and forms complexes with CDK4/6 [4]. Activation of the CDK4/6-cyclin D1 complex contributes to the hyperphosphorylation of the retinoblastoma $(\mathrm{Rb})$ protein, which causes inactivation of the cell growth-inhibitory effects by releasing E2F transcription factors and the cell-cycle progression from $\mathrm{G} 1$ to $\mathrm{S}$ phase $[5,6]$. Because of the essential role of this pathway in cell cycle regulation, inhibition of CDK4/6 has been regarded as a promising target for antitumor therapies. Small molecule CDK4/6 inhibitors may block tumor cell growth by 
binding to the ATP-binding domain of CDK4/6 kinase and dephosphorylate $\mathrm{Rb}$ protein, resulting in cell-cycle arrest in G1 phase [7].

The emergence of second-generation selective CDK4/6 inhibitors, which target tumors expressing CDK4/6, has resulted in meaningful prolongation of progression-free survival (PFS), compared with endocrine therapy alone [8]. To date, three orally bioavailable CDK4/6 inhibitors, palbociclib (Ibrance, PD0332991), ribociclib (Kisqali, LEE011) and abemaciclib (Verzenio, LY2834219), have received Food and Drug Administration approval for the treatment of patients with HR +/HER2- metastatic BC. These CDK4/6 inhibitors can be administered as monotherapy in heavily pretreated patients and as combination therapy with aromatase inhibitors as initial therapy or with fulvestrant after disease progression following first-line endocrine therapy. However, these treatment options are limited for patients with brain metastases. In a phase 2 study of patients with brain metastases secondary to HR +/HER2- metastatic BC who received abemaciclib, $6 \%$ achieved a confirmed objective intracranial response and $38 \%$ experienced a decrease in the sum of intracranial target lesions [9]. In addition, the intracranial clinical benefit rate (complete response $[\mathrm{CR}]+$ partial response $[\mathrm{PR}]+$ stable disease $[\mathrm{SD}]$ persisting for $\geq 6$ months) was $25 \%$ and median PFS was 4.4 months (95\% CI, 2.6-5.5) [9].

FCN-437c is an oral, second-generation, potent, and selective CDK4/6 inhibitor with no inhibitory activity against CDK1, CDK2, or CDK5. In in vitro studies, FCN437c showed inhibitory effects on cell proliferation in human BC cell lines MCF7 and MCF/ARO, which were comparable to or greater than ribociclib and palbociclib. The synergistic antitumor effects of FCN-437c combined with fulvestrant on MCF7 cells and xenograft models were comparable to ribociclib and palbociclib: the antitumor effect of FCN-437c on MCF7/ARO xenograft models was more potent than ribociclib and palbociclib. In addition, results of nonclinical studies have shown that FCN-437c has favorable physical and pharmacokinetic $(\mathrm{PK})$ properties with good penetration through the blood-brain barrier, and an acceptable toxicity profile.

\section{Methods}

\section{Study design and treatment}

This was a phase $1 \mathrm{a}$, multicenter, open-label, single-arm dose-escalation study of FCN-437c in female patients with advanced HR +/HER2- BC. The primary objective of the study was to evaluate safety/tolerability and to determine the maximum tolerated dose (MTD) of FCN-437c as a single agent. In addition, this study evaluated the PK characteristics of FNC-437c as a single dose and continuous doses and assessed preliminary antitumor activity.

Dose escalation $(50,100,200,300,450$, and $600 \mathrm{mg}$ daily) was conducted following a $3+3$ study design. Patients were administered a single oral dose of $\mathrm{FCN}-437 \mathrm{c}$ under fasting conditions for a PK run-in of 7 days, and continuous treatment once daily for 21 days (28-day cycles). Doselimiting toxicities (DLTs) were evaluated during the DLT observation period, including the PK run-in period (7 days) and the first cycle (28 days). The MTD was considered as the highest dose level, with no more than $33 \%$ of DLTs of assessable patients during the DLT evaluation period. All screened patients provided signed informed consent and agreed to comply with the study protocol. This study was conducted in accordance with the Declaration of Helsinki and guidelines for Good Clinical Practice as defined by the International Conference on Harmonization.

\section{Patients}

Adult (aged $\geq 18$ years) female patients with a histological or cytological confirmation of HR +/HER2- advanced $\mathrm{BC}$ whose disease progressed after standard therapy or for which no standard therapy was available were eligible for this study. Patients were required to have at least one measurable lesion based on Response Evaluation Criteria in Solid Tumors (RECIST) version 1.1, or only to have bone metastatic lesions, and an Eastern Cooperative Oncology Group (ECOG) performance status score of 0 or 1. Patients who recently underwent major surgery or received chemotherapy, radiotherapy, antibodies, or other investigational drugs within 28 days of enrollment, or who were previously treated with any CDK4/6 inhibitor, were excluded. Patients were also excluded if they had uncontrolled central nervous system metastases or significant cardiac dysfunction or disease.

\section{Safety assessments}

Dose-limiting toxicities were assessed within 7 days of treatment initiation (PK run-in period) and within 28 days of treatment initiation. A DLT was defined as (1) hematological toxicities: grade 4 neutropenia lasting $\geq 3$ days; grade 3 thrombocytopenia with hemorrhage; grade 3 or 4 febrile neutropenia $\left(>38{ }^{\circ} \mathrm{C}\right.$ for $1 \mathrm{~h}$ or $>38.3{ }^{\circ} \mathrm{C}$ ); (2) nonhematological toxicities (alopecia excluded): grade 2 increased AST/ALT with grade 2 increased total bilirubin; QTc interval $\geq 501 \mathrm{~ms}$ (mean value of at least two ECGs) or QTc interval prolongation $\geq 60 \mathrm{~ms}$ from baseline; grade 3 nausea, vomiting and/or diarrhea, electrolyte disturbances lasting for more than 3 days, which could not be controlled or recovered to grade 1 with supportive care; and other nonspecified $\geq$ grade 3 nonhematological toxicities; and (3) adverse events (AEs) leading to dose suspension for more 
than 28 days or intolerable AEs with clinical significance as judged by the investigator. Adverse events were graded according to the National Cancer Institute's Common Terminology Criteria for Adverse Events, v4.03.

\section{Pharmacokinetic assessments}

Blood samples for single-dose PK evaluation were collected pre-dose and at $0.5,1,2,3,4,6,8,12,24,48,72,120$, and $168 \mathrm{~h}(\mathrm{~s})$ post-dose. Blood samples for multidose PK evaluation were collected on Cycle 1 Day 21 (pre-dose and 0.5, 1, 2, 3, 4, 6, 8, and $12 \mathrm{~h}$ [s] post-dose), Day 22 (24 h post-dose), Day 23 (48 h post-dose), Day 24 (72 h post-dose) and at predose of Cycle 2 Day 1 (192 h post-dose). Steady-state values were calculated by combining data collected at pre-dose of Cycle 1 Days 15, 21, and 22. Plasma samples were assayed using a validated liquid chromatography-tandem mass spectrometry assay.

The PK parameters, including area under the concentration-time curve (AUC) from dosing to the time of the last measured concentration $\left(\mathrm{AUC}_{0 \text {-last }}\right)$, $\mathrm{AUC}$ over the last 24-h dosing interval $\left(\mathrm{AUC}_{0-24}\right)$, AUC to infinite time (AUC $\left.0_{0-\infty}\right)$, maximum concentration $\left(\mathrm{C}_{\max }\right)$, time to maximum concentration $\left(\mathrm{T}_{\max }\right)$, elimination half-life $\left(\mathrm{t}_{1 / 2}\right)$, oral clearance $(\mathrm{CL} / \mathrm{F})$, and accumulation ratio $\left(\mathrm{R}_{\mathrm{AUC}}, \mathrm{RC}_{\max }\right)$, were analyzed and calculated by the noncompartmental model of Phoenix ${ }^{\circledR}$ WinNonlin 6.4 or higher version (Pharsight Corp., Certara, Princeton, NJ, USA) from the individual plasma concentration data of FCN-437c. Plasma concentration and PK parameters of $\mathrm{FCN}-437 \mathrm{c}$ were assessed through descriptive analysis.

\section{Antitumor activity assessments}

Radiographic tumor assessment was performed at screening and once every 8 weeks ( \pm 7 days) until disease progression, intolerable toxicity, or death. Assessments of antitumor activity included confirmed PR or CR, clinical benefit rate (CBR; objective response or SD for $\geq 24$ weeks), and PFS per investigator assessment based on RECIST v1.1.

\section{Statistical methods}

Sample size was estimated based on the $3+3$ study design. All statistical analyses were performed with SAS ${ }^{\circledR} 9.2$ or higher version (SAS Institute, Inc., Cary, NC, USA) except for the calculation of PK parameters with Phoenix ${ }^{\circledR}$ WinNonlin 6.4 or higher version (Pharsight Corp., Certara, Princeton, NJ, USA). The DLTs were summarized by counts and percentages. Safety data were summarized using descriptive statistics in patients who received at least one dose of study treatment (as-treated population). Confirmed ORR, CBR, and 95\% Clopper Pearson confidence intervals were calculated. Evaluation of PFS, duration of response, and overall survival (OS) were performed using Kaplan-Meier analyses per investigator assessment.

\section{Results}

\section{Patients and treatment}

Between February 13, 2019 and April 15, 2020, 17 patients were enrolled at three study centers in Mainland China and received FCN-437c $50 \mathrm{mg}(n=3), 100 \mathrm{mg}(n=3), 200 \mathrm{mg}$ $(n=3), 300 \mathrm{mg}(n=6)$, and $450 \mathrm{mg}(n=2)$. Median age was 45.0 (range, 35-67) years, and most patients (88.2\%) were aged $\leq 65$ years (Supplementary Table 1). All patients $(100 \%)$ failed prior treatment with both hormone therapy and chemotherapy. Twelve patients discontinued treatment, all due to disease progression, and five patients remained on treatment. Five patients completed the study; four patients died and one patient completed the 1-year follow-up per protocol.

As of the data cut-off date of August 10, 2020, the median follow-up duration was 8.71 months (95\% CI: 4.53-10.84). The planned median treatment duration was 112 days (range, 56-216), and the actual median treatment duration was 81 days (range, 43-157). The mean relevant dose intensity was $85.4 \% ; 70.6 \%$ of patients received over $80 \%$ of the planned dose.

\section{Safety and tolerability}

Two patients in the 450-mg dose group experienced DLTs and the dose was regarded as intolerable. No DLT was observed at doses of $300 \mathrm{mg}$ and lower. Table 1 shows study treatment-related AEs (TRAEs) that occurred with a frequency of at least $10 \%$. The most frequently reported hematological TRAEs were leukopenia $(n / N=16 / 17,94.1 \%)$, neutropenia $(n / N=15 / 17,88.2 \%)$, anemia $(n / N=11 / 17,64.7 \%)$, and thrombocytopenia $(n / N=8 / 17,47.1 \%)$. Frequently reported nonhematological TRAEs were prolonged electrocardiogram QT interval $(n / N=5 / 17,29.4 \%)$, hypoalbuminemia $(n / N=5 / 17,29.4 \%)$, and $\operatorname{rash}(n / N=5 / 17,29.4 \%)$. It should be noted that no grade $\geq 3$ non-hematological TRAEs were reported.

There were no dose adjustments or interruptions at the 50-mg or 100-mg dose level. At doses higher than $100 \mathrm{mg}$, six patients required a dose reduction (35.3\%) and 10 patients required a dose interruption $(58.8 \%)$ to manage hematological toxicities. No serious AEs were reported and no TEAEs led to permanent discontinuation of study treatment. There were four deaths reported in the study. One patient died as a result of respiratory failure that was considered unrelated to study treatment. The reasons for the other 
Table 1 TRAEs Occurring in $\geq 10 \%$ of Patients $(N=17)$

\begin{tabular}{|c|c|c|c|c|c|c|c|}
\hline $\mathrm{AE}, n(\%)$ & Grade & $\begin{array}{l}50 \mathrm{mg} \\
(n=3)\end{array}$ & $\begin{array}{l}100 \mathrm{mg} \\
(n=3)\end{array}$ & $\begin{array}{l}200 \mathrm{mg} \\
(n=3)\end{array}$ & $\begin{array}{l}300 \mathrm{mg} \\
(n=6)\end{array}$ & $\begin{array}{l}450 \mathrm{mg} \\
(n=2)\end{array}$ & $\begin{array}{l}\text { Total } \\
(N=17)\end{array}$ \\
\hline \multirow[t]{2}{*}{ Total } & All & $3(100.0)$ & $3(100.0)$ & $3(100.0)$ & $6(100.0)$ & $2(100.0)$ & $17(100.0)$ \\
\hline & Grade 3/4 & $0(0.0)$ & $0(0.0)$ & $3(100.0)$ & $6(100.0)$ & $2(100.0)$ & $11(64.7)$ \\
\hline \multirow[t]{2}{*}{ Leukopenia } & All & $2(66.7)$ & $3(100.0)$ & $3(100.0)$ & $6(100.0)$ & $2(100.0)$ & $16(94.1)$ \\
\hline & Grade 3/4 & $0(0.0)$ & $0(0.0)$ & $2(66.7)$ & $5(83.3)$ & $1(50.0)$ & $8(47.0)$ \\
\hline \multirow[t]{2}{*}{ Neutropenia } & All & $2(66.7)$ & $2(66.7)$ & $3(100.0)$ & $6(100.0)$ & $2(100.0)$ & $15(88.2)$ \\
\hline & Grade 3/4 & $0(0.0)$ & $0(0.0)$ & $3(100.0)$ & $6(100.0)$ & $2(100.0)$ & $11(64.7)$ \\
\hline \multirow[t]{2}{*}{ Anemia } & All & $0(0.0)$ & $0(0.0)$ & $3(100.0)$ & $6(100.0)$ & $2(100.0)$ & $11(64.7)$ \\
\hline & Grade $3 / 4$ & $0(0.0)$ & $0(0.0)$ & $0(0.0)$ & $0(0.0)$ & $0(0.0)$ & $0(0.0)$ \\
\hline \multirow[t]{2}{*}{ Thrombocytopenia } & All & $0(0.0)$ & $0(0.0)$ & $1(33.3)$ & $5(83.3)$ & $2(100.0)$ & $8(47.1)$ \\
\hline & Grade 3/4 & $0(0.0)$ & $0(0.0)$ & $0(0.0)$ & $0(0.0)$ & $1(50.0)$ & $1(5.9)$ \\
\hline \multirow[t]{2}{*}{ Prolonged electrocardiogram QT interval } & All & $1(33.3)$ & $0(0.0)$ & $2(66.7)$ & $2(33.3)$ & $0(0.0)$ & $5(29.4)$ \\
\hline & Grade $3 / 4$ & $0(0.0)$ & $0(0.0)$ & $0(0.0)$ & $0(0.0)$ & $0(0.0)$ & $0(0.0)$ \\
\hline \multirow[t]{2}{*}{ Hypoalbuminemia } & All & $1(33.3)$ & $1(33.3)$ & $1(33.3)$ & $1(16.7)$ & $1(50.0)$ & $5(29.4)$ \\
\hline & Grade 3/4 & $0(0.0)$ & $0(0.0)$ & $0(0.0)$ & $0(0.0)$ & $0(0.0)$ & $0(0.0)$ \\
\hline \multirow[t]{2}{*}{ Rash } & All & $1(33.3)$ & $0(0.0)$ & $2(66.7)$ & $1(16.7)$ & $1(50.0)$ & $5(29.4)$ \\
\hline & Grade 3/4 & $0(0.0)$ & $0(0.0)$ & $0(0.0)$ & $0(0.0)$ & $0(0.0)$ & $0(0.0)$ \\
\hline \multirow[t]{2}{*}{ Increased aspartate aminotransferase } & All & $1(33.3)$ & $0(0.0)$ & $0(0.0)$ & $2(33.3)$ & $1(50.0)$ & $4(23.5)$ \\
\hline & Grade 3/4 & $0(0.0)$ & $0(0.0)$ & $0(0.0)$ & $0(0.0)$ & $0(0.0)$ & $0(0.0)$ \\
\hline \multirow[t]{2}{*}{ Increased blood bilirubin } & All & $0(0.0)$ & $1(33.3)$ & $2(66.7)$ & $0(0.0)$ & $1(50.0)$ & $4(23.5)$ \\
\hline & Grade 3/4 & $0(0.0)$ & $0(0.0)$ & $0(0.0)$ & $0(0.0)$ & $0(0.0)$ & $0(0.0)$ \\
\hline \multirow[t]{2}{*}{ Proteinuria } & All & $2(66.7)$ & $1(33.3)$ & $0(0.0)$ & $1(16.7)$ & $0(0.0)$ & $4(23.5)$ \\
\hline & Grade 3/4 & $0(0.0)$ & $0(0.0)$ & $0(0.0)$ & $0(0.0)$ & $0(0.0)$ & $0(0.0)$ \\
\hline \multirow[t]{2}{*}{ Asthenia } & All & $3(100.0)$ & $0(0.0)$ & $0(0.0)$ & $1(16.7)$ & $0(0.0)$ & $4(23.5)$ \\
\hline & Grade 3/4 & $0(0.0)$ & $0(0.0)$ & $0(0.0)$ & $0(0.0)$ & $0(0.0)$ & $0(0.0)$ \\
\hline \multirow[t]{2}{*}{ Fatigue } & All & $0(0.0)$ & $0(0.0)$ & $1(33.3)$ & $2(33.3)$ & $1(50.0)$ & $4(23.5)$ \\
\hline & Grade 3/4 & $0(0.0)$ & $0(0.0)$ & $0(0.0)$ & $0(0.0)$ & $0(0.0)$ & $0(0.0)$ \\
\hline \multirow[t]{2}{*}{ Increased alanine aminotransferase } & All & $1(33.3)$ & $0(0.0)$ & $0(0.0)$ & $1(16.7)$ & $1(50.0)$ & $3(17.6)$ \\
\hline & Grade 3/4 & $0(0.0)$ & $0(0.0)$ & $0(0.0)$ & $0(0.0)$ & $0(0.0)$ & $0(0.0)$ \\
\hline \multirow[t]{2}{*}{ Hypercholesterolemia } & All & $0(0.0)$ & $0(0.0)$ & $3(100.0)$ & $0(0.0)$ & $0(0.0)$ & $3(17.6)$ \\
\hline & Grade 3/4 & $0(0.0)$ & $0(0.0)$ & $0(0.0)$ & $0(0.0)$ & $0(0.0)$ & $0(0.0)$ \\
\hline \multirow[t]{2}{*}{ Hyperglycemia } & All & $0(0.0)$ & $0(0.0)$ & $1(33.3)$ & $1(16.7)$ & $1(50.0)$ & $3(17.6)$ \\
\hline & Grade 3/4 & $0(0.0)$ & $0(0.0)$ & $0(0.0)$ & $0(0.0)$ & $0(0.0)$ & $0(0.0)$ \\
\hline \multirow[t]{2}{*}{ Hypertriglyceridemia } & All & $0(0.0)$ & $1(33.3)$ & $1(33.3)$ & $1(16.7)$ & $0(0.0)$ & $3(17.6)$ \\
\hline & Grade 3/4 & $0(0.0)$ & $0(0.0)$ & $0(0.0)$ & $0(0.0)$ & $0(0.0)$ & $0(0.0)$ \\
\hline \multirow[t]{2}{*}{ Abdominal pain upper } & All & $1(33.3)$ & $0(0.0)$ & $1(33.3)$ & $0(0.0)$ & $1(50.0)$ & $3(17.6)$ \\
\hline & Grade 3/4 & $0(0.0)$ & $0(0.0)$ & $0(0.0)$ & $0(0.0)$ & $0(0.0)$ & $0(0.0)$ \\
\hline \multirow[t]{2}{*}{ Diarrhea } & All & $0(0.0)$ & $1(33.3)$ & $0(0.0)$ & $1(16.7)$ & $1(50.0)$ & $3(17.6)$ \\
\hline & Grade 3/4 & $0(0.0)$ & $0(0.0)$ & $0(0.0)$ & $0(0.0)$ & $0(0.0)$ & $0(0.0)$ \\
\hline \multirow[t]{2}{*}{ Pruritus } & All & $0(0.0)$ & $0(0.0)$ & $1(33.3)$ & $2(33.3)$ & $0(0.0)$ & $3(17.6)$ \\
\hline & Grade 3/4 & $0(0.0)$ & $0(0.0)$ & $0(0.0)$ & $0(0.0)$ & $0(0.0)$ & $0(0.0)$ \\
\hline \multirow[t]{2}{*}{ Hyperuricemia } & All & $0(0.0)$ & $1(33.3)$ & $1(33.3)$ & $0(0.0)$ & $0(0.0)$ & $2(11.8)$ \\
\hline & Grade 3/4 & $0(0.0)$ & $0(0.0)$ & $0(0.0)$ & $0(0.0)$ & $0(0.0)$ & $0(0.0)$ \\
\hline Hypocalcemia & All & $0(0.0)$ & $2(66.7)$ & $0(0.0)$ & $0(0.0)$ & $0(0.0)$ & $2(11.8)$ \\
\hline & Grade 3/4 & $0(0.0)$ & $0(0.0)$ & $0(0.0)$ & $0(0.0)$ & $0(0.0)$ & $0(0.0)$ \\
\hline Constipation & All & $0(0.0)$ & $0(0.0)$ & $1(33.3)$ & $1(16.7)$ & $0(0.0)$ & $2(11.8)$ \\
\hline & Grade 3/4 & $0(0.0)$ & $0(0.0)$ & $0(0.0)$ & $0(0.0)$ & $0(0.0)$ & $0(0.0)$ \\
\hline Nausea & All & $0(0.0)$ & $0(0.0)$ & $1(33.3)$ & $1(16.7)$ & $0(0.0)$ & $2(11.8)$ \\
\hline & Grade 3/4 & $0(0.0)$ & $0(0.0)$ & $0(0.0)$ & $0(0.0)$ & $0(0.0)$ & $0(0.0)$ \\
\hline
\end{tabular}


Table 1 (continued)

\begin{tabular}{|c|c|c|c|c|c|c|c|}
\hline $\mathrm{AE}, n(\%)$ & Grade & $\begin{array}{l}50 \mathrm{mg} \\
(n=3)\end{array}$ & $\begin{array}{l}100 \mathrm{mg} \\
(n=3)\end{array}$ & $\begin{array}{l}200 \mathrm{mg} \\
(n=3)\end{array}$ & $\begin{array}{l}300 \mathrm{mg} \\
(n=6)\end{array}$ & $\begin{array}{l}450 \mathrm{mg} \\
(n=2)\end{array}$ & $\begin{array}{l}\text { Total } \\
(N=17)\end{array}$ \\
\hline \multirow[t]{2}{*}{ Stomatitis } & All & $0(0.0)$ & $0(0.0)$ & $2(66.7)$ & $0(0.0)$ & $0(0.0)$ & $2(11.8)$ \\
\hline & Grade 3/4 & $0(0.0)$ & $0(0.0)$ & $0(0.0)$ & $0(0.0)$ & $0(0.0)$ & $0(0.0)$ \\
\hline \multirow[t]{2}{*}{ Vomiting } & All & $0(0.0)$ & $0(0.0)$ & $1(33.3)$ & $1(16.7)$ & $0(0.0)$ & $2(11.8)$ \\
\hline & Grade 3/4 & $0(0.0)$ & $0(0.0)$ & $0(0.0)$ & $0(0.0)$ & $0(0.0)$ & $0(0.0)$ \\
\hline \multirow[t]{2}{*}{ Decreased weight } & All & $1(33.3)$ & $0(0.0)$ & $1(33.3)$ & $0(0.0)$ & $0(0.0)$ & $2(11.8)$ \\
\hline & Grade $3 / 4$ & $0(0.0)$ & $0(0.0)$ & $0(0.0)$ & $0(0.0)$ & $0(0.0)$ & $0(0.0)$ \\
\hline \multirow[t]{2}{*}{ Increased weight } & All & $0(0.0)$ & $1(33.3)$ & $1(33.3)$ & $0(0.0)$ & $0(0.0)$ & $2(11.8)$ \\
\hline & Grade 3/4 & $0(0.0)$ & $0(0.0)$ & $0(0.0)$ & $0(0.0)$ & $0(0.0)$ & $0(0.0)$ \\
\hline \multirow[t]{2}{*}{ Pyrexia } & All & $0(0.0)$ & $0(0.0)$ & $1(33.3)$ & $1(16.7)$ & $0(0.0)$ & $2(11.8)$ \\
\hline & Grade 3/4 & $0(0.0)$ & $0(0.0)$ & $0(0.0)$ & $0(0.0)$ & $0(0.0)$ & $0(0.0)$ \\
\hline
\end{tabular}

$A E$ adverse event, TRAE treatment-related adverse event

three deaths were unknown. All patients were in compliance of study drug (median, 100\% [range, 99\%-100\%]).

\section{Pharmacokinetic characteristics}

The plasma concentration-time data and PK profile of FCN437c were determined in all 17 patients following a single dose on Day 1 (Fig. 1a, b, and Table 2) and multiple doses on Cycle 1 Day 21 (Fig. 1c, d, and Table 2). The correlation of exposure and dose after multidose administration was analyzed (Supplementary Table 2).

\section{On single-dose administration}

FCN-437c was absorbed rapidly with a median $\mathrm{T}_{\max }$ ranging from 3.0 to $3.5 \mathrm{~h}$. Mean $\mathrm{t}_{1 / 2}$ ranged from 37.1 to $50.6 \mathrm{~h}$. Mean apparent volume of distribution per unit of body weight ranged from 4020 to $13,210 \mathrm{~mL} / \mathrm{Kg}$ (Table 2). The exposure $\left(\mathrm{C}_{\max }\right.$ and $\left.\mathrm{AUC}_{0-\infty}\right)$ increased almost in proportion with doses ranging from 50 to $450 \mathrm{mg}$.

\section{On multidose administration}

Mean $\mathrm{C}_{\max }$, average steady-state concentration from $0 \mathrm{~h}$ after administration to $24 \mathrm{~h}\left(\mathrm{C}_{\mathrm{av}-\mathrm{ss}} 24 \mathrm{~h}\right), \mathrm{AUC}_{0-\infty}$, and $\mathrm{AUC}_{0-24}$ ranged from 378-1723 ng/ml, 245-1136 ng/ml, 18,568-71,273 ng•h/mL, and 5889-27,253 ng•h/mL, respectively, for doses ranging from 50 to $200 \mathrm{mg}$. After repeated administration, FCN-437c accumulated in the human body. Mean accumulation ratio for $\mathrm{AUC}_{0-\infty}\left(\mathrm{R}_{\mathrm{AUC}}\right)$ and $\mathrm{C}_{\max }$ $\left(\mathrm{R}_{\mathrm{Cmax}}\right)$ ranged from 1.59-3.12 and 1.24-1.63, respectively (Table 2). The exposure increased almost in proportion with dose following multidose administration from 50 to $200 \mathrm{mg}$. After multidose administration of the doses ranging from 200 to $450 \mathrm{mg}$, there appeared to be a trend of saturation.

\section{Antitumor activity}

Among 15 patients with post-baseline assessments, nine patients experienced SD (60\%) (Table 3 and Fig. 2a). At the time of data cut-off, one patient had maintained SD for over 6 months (Fig. 2b); the CBR was 6.7\%. Median PFS was 3.91 months (95\% CI: 2.07-7.62), and median OS had not been reached at the time of analysis.

\section{Discussion}

This phase 1a dose-escalation study enrolled adult female patients with advanced/metastatic $\mathrm{HR}+/ \mathrm{HER} 2-\mathrm{BC}$ to evaluate the safety and tolerability of FCN-437c, an oral CDK4/6 inhibitor. Preliminary data from the 17 patients who participated in the study demonstrated an acceptable safety profile for FCN-437c. Most reported AEs were hematologic in nature and included leukopenia, neutropenia, and anemia, which were manageable and reversible with supportive care and were strongly correlated with dose level. Two patients in the 450-mg dose group experienced DLTs in the third week after the initiation of the first cycle in the continuous dose treatment period: one grade 4 thrombocytopenia that lasted for 11 days and one grade 4 leukopenia that lasted for 7 days. No DLTs were reported in patients who received doses of $300 \mathrm{mg}$ and lower. Neutropenia and leukopenia were the most frequently reported grade 3 and 4 AEs that occurred in patients who received FCN-437c in doses of 200 to $450 \mathrm{mg}$ and were the AEs that most commonly led to dose reduction and dose interruption. In general, the toxicity profile of FCN-437c is similar to that established for palbociclib and ribociclib [10, 11]. For example, hematologic toxicities are the most commonly reported AEs of any grade among patients treated with palbociclib and ribociclib and the most frequently reported grade $3 / 4 \mathrm{AE}$ is neutropenia $[10,11]$. 

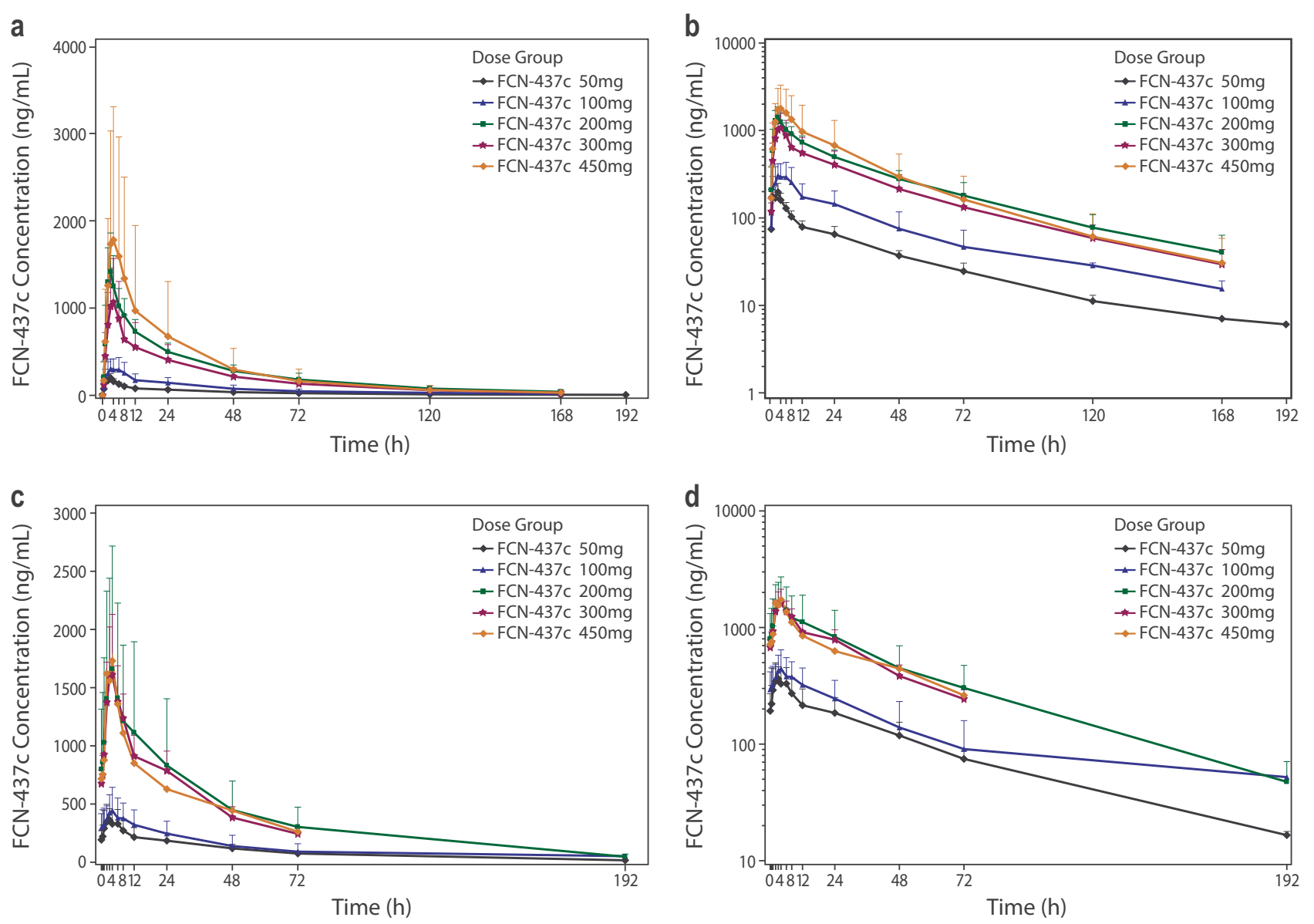

Fig. 1 Mean plasma concentrations of FCN-437c versus time by dose level following a single dose (linear scale); b single dose (semi-log scale); c multiple doses (linear scale); d multiple doses (semi-log scale)

Patients who received FCN-437c also experienced mildto-moderate nonhematologic AEs, all of which were grade 1 or 2. Prolonged electrocardiogram QT interval, hypoalbuminemia, and rash were the most commonly reported nonhematological toxicities. Of note, grade 1 or grade 2 QTcF prolongation was reported in five patients (29.4\%). In contrast, a high frequency of prolonged QTc interval has been reported in patients treated with ribociclib [12]. Results from the MONALEESA-7 study showed an increase of more than $60 \mathrm{~ms}$ from baseline in the QTcF interval in 32 of $335(10 \%)$ patients in the ribociclib group; this AE led to dose interruptions or dose reductions in $13(4 \%)$ patients [12]. Abemaciclib, however, is associated with lower rates of hematological toxicities, such as grade 3/4 neutropenia $(21.1 \%)$, and higher rates of diarrhea, nausea, fatigue, and increased creatinine [13, 14]; none of these AEs were commonly reported in the current study.

Results of the current study showed that when administered as a single dose, the exposure $\left(\mathrm{C}_{\max }\right.$ and $\left.\mathrm{AUC}_{0-\infty}\right)$ of FCN-437c increased almost in proportion with doses from 50 to $450 \mathrm{mg}$. When FCN-437c was administered in multiple doses, the exposure $\left(\mathrm{C}_{\max }, \mathrm{AUC}_{0-\infty}, \mathrm{AUC}_{0-24}, \mathrm{C}_{\mathrm{av}-\mathrm{ss} 24 \mathrm{~h}}\right)$ also increased almost in proportion with doses from 50 to $200 \mathrm{mg}$. The concentration of FCN-437c reached steady state at Cycle 1 Day 15. As the FCN-437c dose increased from 50 to $200 \mathrm{mg}$, the average trough concentration increased in nearly equal proportion after multidose administration. At multidose administration of higher doses (200 to $450 \mathrm{mg}$ ), there appeared to be a trend of saturation. Elimination characteristics of FCN-437c were similar between single doses and multiple doses at all dose levels. After repeated administration, FCN-437c accumulated in the human body. Mean accumulation ratio for $\mathrm{AUC}_{0-\infty}$ and $\mathrm{C}_{\max }$ ranged from 1.59 to 3.12 and from 1.24 to 1.63 , respectively. Results of a multidisciplinary review of the PK characteristics of ribociclib from the CLEE011X2101 study showed that there is a large variation between individuals $\left(\mathrm{C}_{\max }\right.$ range, $859-5860 \mathrm{ng} / \mathrm{ml}$; $\mathrm{AUC}_{0-24 \mathrm{~h}}$ range, $\left.9960-89,600 \mathrm{ng} \cdot \mathrm{h} / \mathrm{ml}\right)[15,16]$. In addition, FCN-437c exposure appears to be higher than ribociclib exposure. Following a single dose, the mean $\mathrm{C}_{\max }$ of $\mathrm{FCN}$ $437 \mathrm{c} 200 \mathrm{mg}(1477 \pm 376 \mathrm{ng} / \mathrm{ml})$ was higher than the mean $\mathrm{C}_{\max }$ of ribociclib $600 \mathrm{mg}$ (geometric mean, 933 [340-3200] 
Table 2 Pharmacokinetic Parameters of FCN-437c

\begin{tabular}{|c|c|c|c|c|c|}
\hline Mean \pm SD & $50 \mathrm{mg}$ & $100 \mathrm{mg}$ & $200 \mathrm{mg}$ & $300 \mathrm{mg}$ & $450 \mathrm{mg}$ \\
\hline \multicolumn{6}{|c|}{ Day 1: Following single dose } \\
\hline $\mathrm{C}_{\max }(\mathrm{ng} / \mathrm{mL})$ & $240 \pm 78.9$ & $316 \pm 121$ & $1477 \pm 376$ & $1092 \pm 489$ & 1839 \\
\hline $\mathrm{T}_{\max }(\mathrm{h})^{\mathrm{a}}$ & $3.00(1.00 \sim 3.00)$ & $3.00(1.00 \sim 4.00)$ & $3.00(2.00 \sim 3.00)$ & $3.50(2.00 \sim 4.00)$ & $3.50(3.00 \sim 4.00)$ \\
\hline $\mathrm{AUC}_{0-\infty}(\mathrm{ng} \bullet \mathrm{h} / \mathrm{mL})$ & $6115 \pm 1015$ & $12,003 \pm 6242$ & $45,146 \pm 12,812$ & $34,648 \pm 13,642$ & 51,591 \\
\hline $\mathrm{t}_{1 / 2}(\mathrm{~h})$ & $50.6 \pm 3.42$ & $40.9 \pm 14.0$ & $42.5 \pm 3.18$ & $43.6 \pm 9.50$ & 37.1 \\
\hline MRT (h) & $58.7 \pm 9.06$ & $48.7 \pm 13.3$ & $50.1 \pm 6.96$ & $51.9 \pm 15.0$ & 40.2 \\
\hline $\mathrm{Vd} / \mathrm{F}(\mathrm{mL} / \mathrm{kg})$ & $9893 \pm 1057$ & $8674 \pm 2537$ & $4020 \pm 1079$ & $9765 \pm 3341$ & 13,210 \\
\hline $\mathrm{Cl} / \mathrm{F}(\mathrm{mL} / \mathrm{h} / \mathrm{kg})$ & $136 \pm 11.3$ & $173 \pm 118$ & $66.3 \pm 20.7$ & $158 \pm 62.4$ & 248 \\
\hline \multicolumn{6}{|c|}{ Cycle 1 Day 21: Following multiple doses } \\
\hline $\mathrm{C}_{\max }(\mathrm{ng} / \mathrm{mL})$ & $378 \pm 122$ & $469 \pm 179$ & $1723 \pm 983$ & $1653 \pm 457$ & 1730 \\
\hline $\mathrm{T}_{\max }(\mathrm{h})^{\mathrm{a}}$ & $3.00(2.00 \sim 3.00)$ & $4.00(3.00 \sim 8.00)$ & $4.00(3.00 \sim 4.00)$ & $4.00(3.00 \sim 4.00)$ & 4 \\
\hline $\mathrm{AUC}_{0-\infty}(\mathrm{ng} \cdot \mathrm{h} / \mathrm{mL})$ & $18,568 \pm 4437$ & $22,566 \pm 16,691$ & $71,273 \pm 35,143$ & $56,592 \pm 12,149$ & 58,803 \\
\hline$t_{1 / 2}(h)$ & $52.1 \pm 8.20$ & $38.8 \pm 24.3$ & $45.1 \pm 14.1$ & $27.9 \pm 2.67$ & 36.6 \\
\hline $\mathrm{R}_{\mathrm{AUC}}$ & $3.12 \pm 1.00$ & $1.88 \pm 0.701$ & $1.61 \pm 0.819$ & $1.59 \pm 0.456$ & 3.04 \\
\hline $\mathrm{Vd} / \mathrm{F}(\mathrm{mL} / \mathrm{kg})$ & $3531 \pm 1312$ & $4222 \pm 894$ & $3301 \pm 2243$ & $3408 \pm 704$ & 6858 \\
\hline $\mathrm{Cl} / \mathrm{F}(\mathrm{mL} / \mathrm{h} / \mathrm{kg})$ & $46.0 \pm 11.7$ & $98.7 \pm 58.6$ & $47.6 \pm 26.1$ & $86.1 \pm 24.4$ & 130 \\
\hline $\mathrm{R}_{\mathrm{Cmax}}$ & $1.63 \pm 0.458$ & $1.58 \pm 0.525$ & $1.24 \pm 0.838$ & $1.50 \pm 0.643$ & 2.12 \\
\hline $\mathrm{AUC}_{0-24}(\mathrm{ng} \bullet \mathrm{h} / \mathrm{mL})$ & $5889 \pm 2138$ & $7871 \pm 3109$ & $27,253 \pm 17,592$ & $25,098 \pm 5019$ & 23,615 \\
\hline $\mathrm{C}_{\mathrm{av}-\mathrm{ss} 24 \mathrm{~h}}(\mathrm{ng} / \mathrm{mL})$ & $245 \pm 89.1$ & $328 \pm 130$ & $1136 \pm 733$ & $1046 \pm 209$ & 984 \\
\hline $\mathrm{DF}_{24 \mathrm{~h}^{\mathrm{b}}}^{\mathrm{b}}$ & $0.802 \pm 0.222$ & $0.712 \pm 0.245$ & $0.863 \pm 0.236$ & $0.820 \pm 0.194$ & 1.12 \\
\hline
\end{tabular}

$A U C_{0-\infty}$ area under the curve from $0 \mathrm{~h}$ after administration to infinite time point, $A U C_{0-24}$ area under the curve from $0 \mathrm{~h}$ after administration to $24 \mathrm{~h}, C_{\mathrm{av}-\mathrm{ss}} 24 \mathrm{~h}$ average steady-state concentration from $0 \mathrm{~h}$ after administration to $24 \mathrm{~h}, C l / F$ apparent volume of the central compartment cleared of drug per unit time, $C_{\max }$ maximum concentration, $D F_{24 \mathrm{~h}}$ degree of steady-state concentration fluctuation from $0 \mathrm{~h}$ after administration to $24 \mathrm{~h}, M R T$ mean residence time, $R_{\mathrm{AUC}}$ ratio of $\mathrm{AUC}_{0-\infty}, R C_{\max }$ ratio of maximum concentration, $t_{1 / 2}$ terminal half-life, $T_{\max }$ time to $\mathrm{C}_{\max }, V d / F$ apparent volume of distribution per unit of body weight

${ }^{\mathrm{a}} \mathrm{T}_{\max }(\mathrm{h})$ is presented as median (range)

${ }^{\mathrm{b}} \mathrm{DF}_{24 \mathrm{~h}}=100 \% \times\left(\mathrm{C}_{\max }-\mathrm{C}_{\min }\right) / \mathrm{C}_{\mathrm{av}-\mathrm{ss}} 24 \mathrm{~h}$

ng•h/ml). Following multiple doses, the FCN-437c $\mathrm{C}_{\max }$ $(1723 \pm 983 \mathrm{ng} / \mathrm{ml})$ and $\mathrm{AUC}_{0-24}(27,253 \pm 17,592 \mathrm{ng} \bullet \mathrm{h} / \mathrm{ml})$ in the 200-mg dose group were similar to ribociclib's $\mathrm{C}_{\max }$ (geometric mean, 1940 [range, 859-5860] ng/ml) and AUC

Table 3 Clinical Antitumor Activity of Single Agent FCN-437c

\begin{tabular}{ll}
\hline & Total $(N=15)$ \\
\hline Best overall response, $n(\%)$ & \\
Complete response & $0(0.0 \%)$ \\
Partial response & $0(0.0 \%)$ \\
Stable disease & $9(60.0 \%)$ \\
Progressive disease & $6(40.0 \%)$ \\
Not evaluable & $0(0.0 \%)$ \\
ORR, \% (95\% CI) & $0.0 \%(0.00 \%-21.80 \%)$ \\
CBR, \% (95\% CI) & $6.7 \%(0.17 \%-31.95 \%)$ \\
Median PFS, months $(95 \% \mathrm{CI})$ & $3.91(2.07-7.62)$ \\
Median OS, months $(95 \% \mathrm{CI})$ & NR $(7.98-\mathrm{NA})$
\end{tabular}

$C B R$ clinical benefit rate, NA not applicable, NR not reached, ORR objective response rate, $O S$ overall survival, $P F S$ progression-free survival

${ }^{a} \mathrm{CBR}$ is defined as the proportion of patients with confirmed complete response + partial response + stable disease lasting for $\geq 6$ months
0-24 h (geometric mean, 26,600 [range, 9960-89600] ng•h/ $\mathrm{ml}$ ) in the 600-mg dose group.

Results of the current study established the MTD of FCN$437 \mathrm{c}$ as $300 \mathrm{mg}$ once daily based on the occurrence of grade 3 or 4 hematologic AEs and the rate of dose interruptions and adjustments that occurred with this dose. In addition, there appears to be a trend of the exposure saturation from 200 to $450 \mathrm{mg}$, thus the recommended phase 2 dose of FCN$437 \mathrm{c}$ was proposed as $200 \mathrm{mg}$.

Results of studies that assessed the three marketed CDK4/6 inhibitors showed that combination therapies with endocrine agents (aromatase inhibitors or fulvestrant) significantly improved PFS and OS over the placebo plus endocrine agents in patients with $\mathrm{HR}+/$ HER2- metastatic BC in first- and second-line settings, regardless of endocrine therapy strategies, treatment lines, number of metastatic sites, or menopausal status [17, 18]. However, minor antitumor activity was demonstrated with single-agent palbociclib or ribociclib. Few patients achieved PRs and approximately $30 \%$ of patients experienced SD in phase 1 trials [19-21]. In the phase 2 MONARCH-1 study, abemaciclib alone showed a confirmed ORR of $19.7 \%$ and a CBR of $42.4 \%$ among 

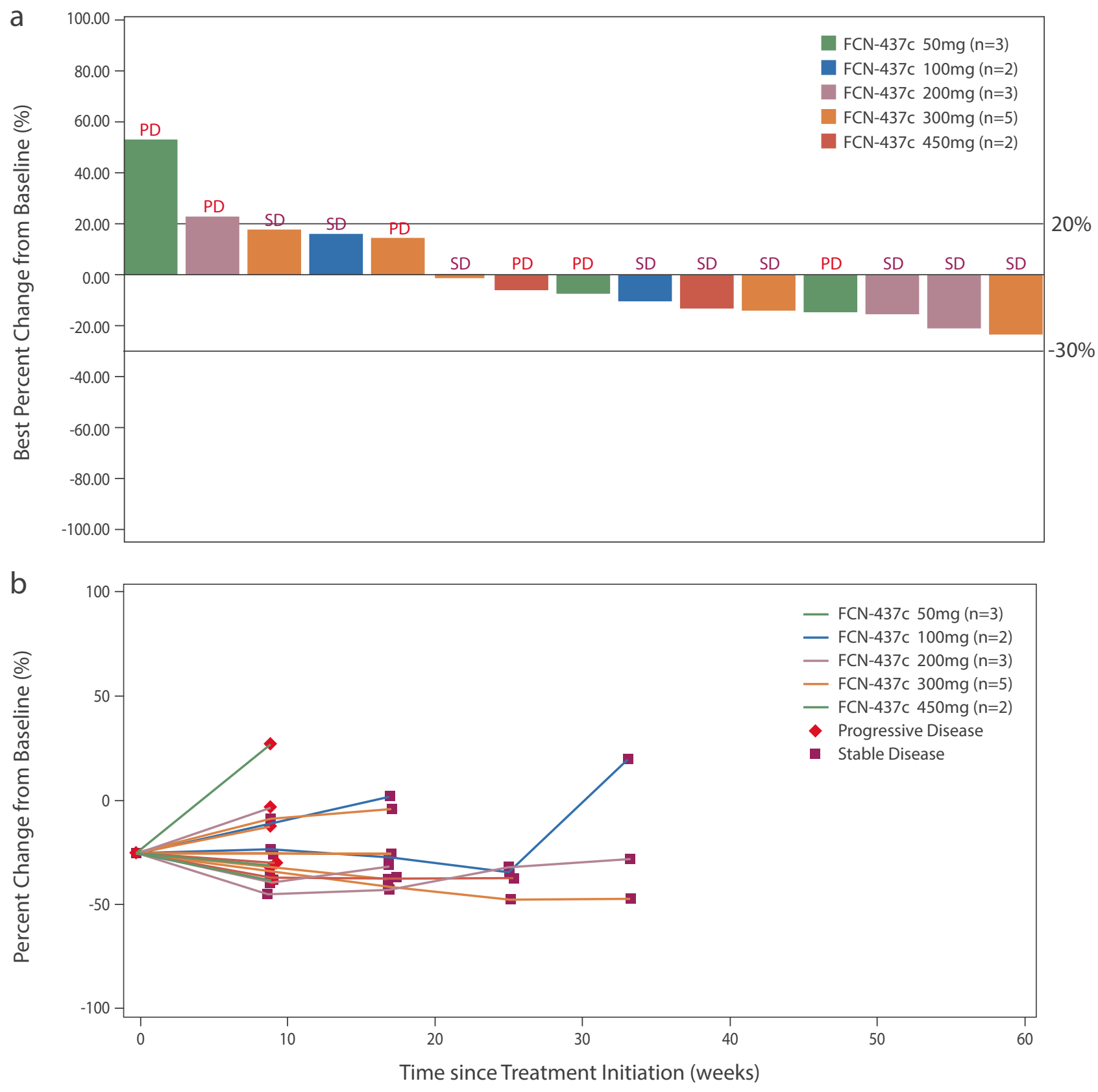

Fig. 2 a Waterfall plot and $\mathbf{b}$ spider plot of best percentage change from baseline in sum of diameters by dose level

132 heavily pretreated patients; median PFS was 6.0 months and median OS was 17.7 months [22]. Based on these results, abemaciclib has become the only CDK4/6 inhibitor approved as monotherapy for the treatment of patients with HR + /HER2- advanced BC whose disease progressed following prior endocrine therapy and chemotherapy.

Similar to palbociclib and ribociclib, FCN-437c as monotherapy showed modest antitumor activity; however, $60 \%$ of the patients experienced durable $\mathrm{SD}$, which suggests potential for improved antitumor activity when combined with hormone therapy. Results of the current study warrant further exploration of FCN-437c combination therapy in phase 2 studies.

In conclusion, this study showed that single-agent FCN$437 \mathrm{c}$ administered on a $3 / 1$ schedule has a favorable safety profile. Most toxicities were hematologic in nature and were generally tolerable and manageable. FCN-437c $200 \mathrm{mg}$ is the proposed recommended phase 2 dose based on the comprehensive assessment of safety and PK in the current study. Preliminary results showing that $60 \%$ of patients who received single-agent $\mathrm{FCN}-437 \mathrm{c}$ experienced SD warrant 
further exploration in clinical trials, particularly to evaluate $\mathrm{FCN}-437 \mathrm{c}$ in combination with other endocrine therapies. Currently, a phase 2 trial of FCN-437c combined with letrozole or fulvestrant in female patients with advanced/ metastatic HR +/HER2- BC is ongoing.

Supplementary Information The online version contains supplementary material available at https://doi.org/10.1007/s10637-021-01133-2.

Acknowledgements We thank the patients and families for participating in this trial. We also thank the investigators and the staff who took care of the patients at the investigative sites, and the members of the data management and statistics team and project management team of Beijing Fosun Pharmaceutical Research and Development Co., Ltd. for data analysis and project management.

Author contributions Conceptualization: Aimin Hui, Zhuli Wu, Xichun Hu Funding acquisition: Ling Tian Investigation: Jian Zhang, Xiaojia Wang, Xian Wang, Xichun Hu Project administration: Zhuli Wu, Yuchen Yang Resources: Ling Tian Supervision: Aimin Hui, Zhuli Wu Visualization: Jian Zhang Writing - original draft: Yuchen Yang, Wenjing Zhang Writing - review \& editing: Jian Zhang, Aimin Hui, Zhuli Wu, Changjiang Xu, Xichun Hu.

Funding All funding was provided by Avanc Pharmaceutical Co., Ltd.

\section{Declarations}

Ethics approval All procedures performed in studies involving human participants were in accordance with the ethical standards of the institutional and/or national research committee and with the 1964 Declaration of Helsinki and its later amendments or comparable ethical standards. The study was approved by the Ethics Committee of Fudan University Shanghai Cancer Center (No. 1806186-8-1808), Cancer Hospital of the University of Chinese Academy of Sciences (No. IRB[2019]619), and Sir Run Run Shaw Hospital (No. 20190927-14).

Consent to participate Informed consent was obtained from all individuals who participated in the study.

Conflicts of interest/competing interests The study was initiated, funded, and sponsored by Avanc Pharmaceutical Co., Ltd. Jian Zhang, Xiaojia Wang, Xian Wang, and Xichun Hu declare no potential conflicts of interest. Aimin Hui is a full-time employee of Fosun Pharma USA Inc. Zhuli Wu, Changjiang Xu, Yuchen Yang, and Wenjing Zhang are full-time employees of Beijing Fosun Pharmaceutical Research and Development Co., Ltd. Ling Tian is a full-time employee of Avanc Pharmaceutical Co., Ltd.

Open Access This article is licensed under a Creative Commons Attribution 4.0 International License, which permits use, sharing, adaptation, distribution and reproduction in any medium or format, as long as you give appropriate credit to the original author(s) and the source, provide a link to the Creative Commons licence, and indicate if changes were made. The images or other third party material in this article are included in the article's Creative Commons licence, unless indicated otherwise in a credit line to the material. If material is not included in the article's Creative Commons licence and your intended use is not permitted by statutory regulation or exceeds the permitted use, you will need to obtain permission directly from the copyright holder. To view a copy of this licence, visit http://creativecommons.org/licenses/by/4.0/.

\section{References}

1. Cancer Facts and Figures (2019) American Cancer Society. https://www.cancer.org/research/cancer-facts-statistics/allcancer-facts-figures/cancer-facts-figures-2019.html. Accessed 21 April 2021

2. Sherr CJ, Beach D, Shapiro GI (2016) Targeting CDK4 and CDK6: From discovery to therapy. Cancer Discov 6:353-367. https://doi.org/10.1158/2159-8290

3. Santamaria D, Ortega S (2006) Cyclins and CDKS in development and cancer: lessons from genetically modified mice. Front Biosci 11:1164-1188. https://doi.org/10.2741/1871

4. Cancer Genome Atlas Network (2012) Comprehensive molecular portraits of human breast tumours. Nature 490(7418):6170. https://doi.org/10.1038/nature 11412

5. Lange CA, Yee D (2011) Killing the second messenger: targeting loss of cell cycle control in endocrine-resistant breast cancer. Endocr Relat Cancer 18(4):C19-24. https://doi.org/10. 1530/ERC-11-0112

6. Spring L, Bardia A, Modi S (2016) Targeting the cyclin D-cyclindependent kinase (CDK) 4/6-retinoblastoma pathway with selective CDK 4/6 inhibitors in hormone receptor-positive breast cancer: rationale, current status, and future directions. Discov Med 2(113):65-74

7. O'Leary B, Finn RS, Turner NC. Treating cancer with selective CDK4/6 inhibitors (2016) Nat Rev Clin Oncol 13(7):417430. https://doi.org/10.1038/nrclinonc.2016.26

8. Piezzo M, Chiodini P, Riemma M, Cocco S, Caputo R, Cianniello D (2020) Progression-free survival and overall survival of CDK 4/6 inhibitors plus endocrine therapy in metastatic breast cancer: a systematic review and meta-analysis. Int J Mol Sci 3;21(17):6400. https://doi.org/10.3390/ijms21176400

9. Anders CK, Le Rhun E, Bachelot TD, Yardley DA, Awada A, Conte PF (2019) A phase II study of abemaciclib in patients (pts) with brain metastases (BM) secondary to HR+, HER2metastatic breast cancer (MBC). J Clin Oncol 37(suppl 15):1017. https://doi.org/10.1200/JCO.2019.37.15_suppl.1017

10. Finn RS, Martin M, Rugo HS, Jones S, Im S-A, Gelmon K (2016) Palbociclib and letrozole in advanced breast cancer. N Engl J Med 17;375(20):1925-1936. https://doi.org/10.1056/ NEJMoa1607303

11. Hortobagyi GN, Stemmer SM, Burris HA, Yap Y-S, Sonke GS, Paluch-Shimon S (2016) Ribociclib as first-line therapy for HRpositive, advanced breast cancer. N Engl J Med 3;375(18):17381748. https://doi.org/10.1056/NEJMoa1609709

12. Tripathy D, Im S-A, Colleoni M, Franke F, Bardia A, Harbeck N (2018) Ribociclib plus endocrine therapy for premenopausal women with hormone-receptor-positive, advanced breast cancer (MONALEESA-7): a randomised phase 3 trial. Lancet Oncol 19(7):904-915. https://doi.org/10.1016/S1470-2045(18)30292-4

13. Sledge Jr GW, Toi M, Neven P, Sohn J, Inoue K, Pivot X (2017) MONARCH 2: Abemaciclib in combination with fulvestrant in women with HR+/HER2- advanced breast cancer who had progressed while receiving endocrine therapy. J Clin Oncol 35(25):2875-2884. https://doi.org/10.1200/JCO.2017.73.7585

14. Goetz MP, Toi M, Campone M, Sohn J, Paluch-Shimon S, Huober J (2017) MONARCH 3: Abemaciclib as initial therapy for advanced breast cancer. J Clin Oncol 35(32):3638-3646. https:// doi.org/10.1200/JCO.2017.75.6155

15. Infante JR, Cassier PA, Gerecitano JF, Witteveen PO, Chugh R, Ribrag V (2016) A phase I study of the cyclin-dependent kinase $4 / 6$ inhibitor ribociclib (LEE011) in patients with advanced solid tumors and lymphomas. Clin Cancer Res 22(23):56965705. https://doi.org/10.1158/1078-0432.CCR-16-1248 
16. Center for Drug Evaluation and Research. NDA/BLA multidisciplinary review and evaluation NDA 209092 KISQALI (ribociclib). Available at: https://www.accessdata.fda.gov/ drugsatfda_docs/nda/2017/209092Orig1s000MultidisciplineR.pdf. Accessed 4 May 2021

17. Piezzo M, Chiodini P, Riemma M, Cocco S, Caputo R, Cianniello D (2020) Progression-free survival and overall survival of CDK 4/6 inhibitors plus endocrine therapy in metastatic breast cancer: a systematic review and meta-analysis. Int J Mol Sci 21(17):6400. https://doi.org/10.3390/ijms21176400

18. Zheng J, Wu J, Wang C, Zhuang S, Chen J, Ye F (2020) Combination cyclin-dependent kinase 4/6 inhibitors and endocrine therapy versus endocrine monotherapy for hormonal receptor-positive, human epidermal growth factor receptor 2-negative advanced breast cancer: A systematic review and meta-analysis. PLoS One 15(6):e0233571. https://doi.org/10.1371/journal.pone.0233571

19. Schwartz GK, LoRusso PM, Dickson MA, Randolph SS, Shaik MN, Wilner KD (2011) Phase I study of PD 0332991, a cyclindependent kinase inhibitor, administered in 3-week cycles (Schedule 2/1). Br J Cancer 104(12):1862-1868. https://doi.org/10.1038/ bjc. 2011.177
20. Flaherty KT, Lorusso PM, Demichele A, Abramson VG, Courtney R, Randolph SS (2012) Phase I, dose-escalation trial of the oral cyclin-dependent kinase 4/6 inhibitor PD 0332991, administered using a 21-day schedule in patients with advanced cancer. Clin Cancer Res 18(2):568-576. https://doi.org/10.1158/1078-0432. CCR-11-0509

21. Doi T, Hewes B, Kakizume T, Tajima T, Ishikawa N, Yamada Y (2018) Phase I study of single-agent ribociclib in Japanese patients with advanced solid tumors. Cancer Sci 109(1):193-198. https:// doi.org/10.1111/cas. 13428

22. Dickler MN, Tolaney SM, Rugo HS, Cortés J, Diéras V, Patt D (2017) MONARCH 1, a phase II study of abemaciclib, a CDK4 and CDK6 inhibitor, as a single agent, in patients with refractory HR +/HER2- metastatic breast cancer. Clin Cancer Res 23(17):5218-5224. https://doi.org/10.1158/1078-0432. CCR-17-0754

Publisher's Note Springer Nature remains neutral with regard to jurisdictional claims in published maps and institutional affiliations. 